\title{
O SABER SURGE DA PRÁTICA: POR UM SERVIÇO SOCIAL COM PERSPECTIVA FEMINISTA
}

\author{
Teresa Kleba Lisboa* \\ Catarina Nascimento de Oliveira**
}

\begin{abstract}
Resumo
O presente artigo propõe uma interlocução entre o Serviço Social e os Estudos Feministas no processo de construção do conhecimento introduzindo a categoria interseccionalidade para legitimar a multiplicidade de diferenças com as quais nos deparamos no cotidiano de nossas práticas. Amparadas na Epistemologia Feminista, questionamos o reducionismo do Serviço Social brasileiro a uma única corrente teórica, o marxismo, que submete toda a complexidade da vida humana à esfera da produção. O texto busca desvendar as fissuras que avançam no campo do conhecimento, no sentido de contribuir com propostas teóricas que atravessam fronteiras interseccionais, transversais, interdisciplinares entre as categorias gênero, raça, etnia, sexualidade, classe, geração entre outras. O percurso argumentativo acompanhará uma sequência de reflexões realizadas ao longo de anos de experiência, tanto na prática acadêmica, como nos trabalhos de campo realizados através de Projetos de Pesquisa e Extensão.
\end{abstract}

Palavras-chave: Serviço social. Epistemologias feministas. Interseccionalidade. Intervenção profissional.

\footnotetext{
* Doutora em Sociologia. Professora Titular do Departamento de Serviço Social (DSS) e do Programa de Pós- Graduação Interdisciplinar em Ciências Humanas (PPGICH) da Universidade Federal de Santa Catarina (UFSC).E-mail: tkleba@gmail.com ** Doutoranda do Programa de Pós-Graduação Interdisciplinar em Ciências Humanas (PPGICH) da UFSC. Professora do Departamento de Serviço Social da Universidade Federal do Sergipe (UFS) - Campus Aracajú. E-mail: catarinanoliveira1@gmail.com
} 


\section{Introdução}

Propomos neste artigo refletir sobre a "produção do conhecimento ${ }^{1}$ em Serviço Social e sua inter-relação com os Estudos Feministas, com o propósito de contribuir para a construção de novas cartografias de saberes. Buscaremos, ao longo do texto, desvendar as fissuras que avançam no campo do conhecimento, em um período de profundas e aceleradas transformações, no sentido de contribuir com propostas teóricas que atravessam as fronteiras interseccionais, transversais, interdisciplinares entre as categorias gênero, raça/etnia ${ }^{2}$, sexualidade, classe, geração entre outras. Reconhecer a multiplicidade das diferenças como dado inerente na constituição dos sujeitos tem gerado uma combinação de discursos e práticas mobilizadoras, tanto das lutas sociais como dos movimentos feministas no Brasil e na América Latina.

Os movimentos de mulheres e as diferentes correntes do feminismo têm desempenhado papel relevante no crescimento da participação feminina no mundo acadêmico e científico. As principais demandas das mulheres surgem dos movimentos, e são eles que sugerem transformar as práticas científicas lançando novas perguntas, teorias e métodos que suponham avanços, tanto no campo cognitivo quanto no enfrentamento das injustiças sociais. No lugar de uma "mulher universal", surgem mulheres diversas, situadas, portadoras de conhecimentos e experiências específicas, talhadas na vivência socioeconômica e cultural de seus marcadores sociais e de sua transterritorialidade entre lugares.

Desde a segunda metade do século XX, no Brasil, a segunda onda feminista já se alçou contra a violência exercida sobre o corpo das mulheres; e mais tarde, a terceira onda permitiu perceber que a violência é contra todo o corpo que carregue a marca da feminilidade, interseccionada com a raça/ etnia, classe, religião, lugar de moradia e/ou nascimento, idade, sexualidade, idioma e uma infinidade de indicadores que reforçam as estratégias de poder sobre os corpos. Nesse sentido, os Estudos Feministas têm se revelado com uma singular capacidade para modificar perspectivas teóricas, e para elaborar ferramentas de resistência para identificar, descrever e explicar, tanto as desigualdades existentes entre mulheres e homens, como os mecanismos de sua reprodução e legitimação. Acreditamos que o feminismo, como movimento político e sociocultural nasce, justamente, para contestar os pressupostos valorativos da modernidade, preocupa-se com a questão da ética, da equidade, da justiça e da igualdade, reivindicando-as como parte integrante de um novo paradigma civilizatório e de um projeto ético político emancipatório.

Isto posto, trazemos para discussão um fato que nos indigna, em relação a formação profissional dos(as) Assistentes Sociais no Brasil: nossa
1 Estamos nos referindo à "Produção do Conhecimento Científico”.

2 Em relação ao conceito "raça", tornou-se usual, especialmente a partir da antropologia que se afirma desde o início do século XX, utilizar a forma "raça/etnia", a qual, conjugando a noção biológica de "raça" com a antropológica de "etnia", normalizará a diferença racial na cultura de massas, tornando "a ideia de 'raça' epistemologicamente correta” (GILROY, 2007, p. 81). Se "raça" engloba características fenotípicas, como a cor da pele, tipo de cabelo, conformação facial e cranial; "etnia" compreende fatores culturais, como a nacionalidade, afiliação tribal, religião, língua e tradições de um determinado grupo. 
3 Segundo Linda Nicholson (2000), nos estudos feministas, a palavra "gênero" é utilizada em pelo menos dois sentidos distintos. A primeira concepção utiliza gênero como construção social, em oposição ao "sexo", que é biologicamente dado. Gênero seria uma interpretação cultural do sexo, e remeteria a personalidade e comportamentos. Em contrapartida, também se utiliza gênero em referência a "qualquer construção social que tenha a ver com a distinção masculino/ feminino, incluindo as construções que separam corpos "femininos" de corpos 'masculinos". Esse uso advém da percepção que a sociedade forma não só a personalidade e o comportamento, mas também as maneiras como o corpo aparece. categoria profissional é formada por $95 \%$ de mulheres, as quais atendem, no cotidiano de intervenção, majoritariamente mulheres-demandatárias, usuárias das políticas sociais, dos serviços e recursos socioassistenciais, cada qual por sua vez, apresentando diferentes marcadores sociais de gênero, classe, raça, etnia, sexualidade, geração, entre outros. Esse cenário nos leva a concluir que a categoria "gênero" é um elemento-chave para compreender e explicar o status do Serviço Social, não só porque formamos parte de uma disciplina e de uma profissão feminizada, mas também porque essa categoria permite desvendar os reducionismos que fundamentam os pressupostos teórico-metodológicos que regem muitos cursos de Serviço Social na América Latina (VILLENA; ROMERO, 2017) e também no Brasil.

A introdução dos Estudos Feministas e de Gênero no campo das Ciências Sociais tem redefinido uma série de temas e áreas de pesquisa permitindo estabelecer conexões entre quem fala e o mundo de que se fala, entre a produção teórica e as concepções da política que nelas emergem. O entendimento de que "as ideias não podem ser separadas dos indivíduos que as criam e compartilham" (COLLINS, 2009, p. 281) evoca as experiências das mulheres e nos faz refletir sobre a dialética entre o epistemológico e o empírico, acreditando que o saber (a investigação social) se nutre da intervenção social (das práticas).

Diante dessa realidade, nós nos perguntamos com esta questão: por que os cursos de Serviço Social no Brasil têm tanta resistência a incorporar disciplinas sobre Estudos Feministas, Relações de Gênero e suas Interseccionalidades nos currículos acadêmicos?

É nesse contexto,e com estes pressupostos valorativos, que gostaríamos de propor uma aproximação entre os Estudos Feministas e o Serviço Social. Acreditando que o foco das teorias feministas não se restringe apenas "a mulheres ou à agenda feminista”, mas que abarca um leque de questões que dizem respeito à política, democracia, equidade e justiça, nosso percurso argumentativo acompanhará uma sequência de reflexões realizadas ao longo de anos de experiência, tanto na prática acadêmica, como professoras das disciplinas "Epistemologias Feministas", "Serviço Social e Relações de Gênero", "Supervisão Pedagógica de Estágio" e orientadoras de inúmeros Trabalhos de Conclusão de Curso de Graduação e Especialização, Dissertações de Mestrado, Teses de Doutorado, como nos trabalhos de campo realizados por meio de Projetos de Pesquisa e Extensão.

\section{Contribuição das Epistemologias Feministas para o Serviço Social}

A Epistemologia é um ramo da filosofia que estuda a definição de saberes e a produção do conhecimento. Também chamada de filosofia da 
ciência, uma metalinguagem, isto é, um conhecimento sobre o conhecimento. Em suma, a epistemologia estuda a pesquisa científica e seu produto: o conhecimento científico (GUZMÁN; PÉREZ, 2005).

O pensamento europeu, legitimado pela era do Iluminismo, construiu o paradigma de homem universal, masculino, heterossexual, branco e ocidental reforçando a superioridade do homem e a invisibilidade da mulher. Ao expressar uma racionalidade na produção do conhecimento, a hegemonia eurocêntrica tem apontado algumas dificuldades, como afirma o sociólogo peruano Aníbal Quijano (1993, p. 95): “[...] a diversidade e a heterogeneidade da história latino-americana obriga a ultrapassar os limites da epistemologia ocidental, cujo paradigma foi definido a partir da racionalidade europeia, a partir de uma relação de exterioridade entre sujeito e objeto".

Feministas contemporâneas juntam-se aos questionamentos referentes ao ideário iluminista, ao imperialismo da razão instrumental, que atribui somente aos homens (brancos, de classe média, ocidentais) a capacidade de propor filosofias, excluindo as mulheres. Propõem, então, uma Epistemologia Feminista que possa desconstruir os binarismos, o logocentrismo, o antropocentrismo para alçar as mulheres a "sujeitos epistêmicos", ou seja, mudar a ideia de que: “[...] as mulheres podiam ser objeto da razão e da observação masculina, mas nunca seus sujeitos [...] somente os homens eram vistos como detentores de conhecimento" (HARDING, 1996, p. 17).

Em seu livro "Ciência e Feminismo", Sandra Harding (1996, p. 15) indaga: "quem pode ser sujeito do conhecimento? Podem sê-lo as mulheres? Quem define o que é ciência e o que é científico? Quem define os tipos de problemas (questões ou situações) que devem ser priorizados como ciência?".

Sabemos que a Ciência é uma forma de discurso sujeito a formulações e critérios daquilo que um determinado grupo que é considerado autoridade valida como verdade. A autora argumenta que as epistemologias tradicionais excluem as mulheres como sujeitos ou agentes do conhecimento, sustentam que a voz da ciência é masculina e que a história foi escrita do ponto de vista dos homens. Em contrapartida a esta visão, as feministas propõem epistemologias alternativas (HARDING, 1996; HARAWAY, 1995; BLAZQUEZ GRAF, 2008; SALGADO, 2008), que coloquem as mulheres no lugar de sujeitos do conhecimento.

A Epistemologia Feminista é proposta, pela primeira vez, por autoras norte-americanas - Sandra Harding e Donna Haraway - e surge na década de 1970, no marco da segunda onda do Feminismo, e "[...] desde suas origens tem se caracterizado por não ser um conjunto teórico uniforme nem responder a um discurso homogêneo" (HARDING, 1996, p. 7). Ao 
contrário, este tipo de discussão é uma necessidade em sociedades com aspirações democráticas e de justiça social, pois engloba uma pluralidade de enfoques e métodos, articulados de forma diferente em distintos países ou áreas de conhecimento.

É importante assinalar que a Epistemologia Feminista é um campo conceitual ainda em elaboração, e entre as especialistas há um acordo sobre três principais tendências: a Teoria do Ponto de Vista (Standpoint); o Empirismo Feminista; o Pós-modernismo Feminista, cujos pontos de distinção ocorrem pela forma como estabelecem a relação entre mulheres e ciência. $\mathrm{O}$ ponto central que serve de referência para essas três tendências é o valor epistemológico outorgado à categoria "experiência" das mulheres. A experiência dá forma às vivências pessoais de uma multiplicidade de sujeitos, é o espaço onde se configura a inter-relação entre as variáveis gênero, raça, etnia, classe entre outras, possibilitando o surgimento de uma subjetividade recriada pelas próprias mulheres e pelos demais sujeitos envolvidos na relação. Resulta particularmente valoroso o caráter situado da experiência, ou seja, ser uma experiência de mulheres ou uma relação entre experiência e gênero. A experiência, portanto, é um constructo teórico, cujo estatuto epistemológico é motivo de reflexão para as tendências que apresentamos a seguir.

A) A Teoria do Ponto de vista Feminista ou Standpoint - Esta tendência considera que as mulheres possuem um privilégio epistêmico devido à sua posição de subordinação (menos vantajosa), o que as permite comportar-se ao mesmo tempo como "próprias" e estranhas (insiders e outsiders) em relação aos grupos a que pertencem e aos que pesquisam. Nega a separação entre sujeito e objeto e propõem que as mulheres estão situadas em posições que lhes permitem ter uma melhor perspectiva ou ponto de vista no processo de criar conhecimentos livres de valores androcêntricos e sexistas. São capazes de ter uma atitude vigilante, uma "dupla visão", ou seja, aprendem a manejar a sua própria cultura e a dominante, incluindo a dos homens que as dominam em seu próprio grupo.

B) O Empirismo Feminista - Nesta tendência os posicionamentos dos sujeitos cognoscentes (pesquisadores) são os que introduzem vieses na atividade científica, gerando a "boa" ou a "má" ciência. Isto é: a "boa ciência" é resultado do rigor científico na investigação; e a "má ciência" se produz quando os preconceitos, valores, vieses se antepõem ao procedimento científico. Considera-se que os enviesamentos sexistas e androcêntricos surgem no processo de pesquisa e, por sua vez, são corrigíveis mediante a estrita adesão às normas metodológicas vigentes da investigação científica. O empirismo feminista sustenta que a virada epistêmica radica no ato de "fazer ciência com perspectiva feminista".

C) O Pós-Modernismo Feminista - Uma terceira perspectiva, segundo Sandra Harding (1996, p. 25), assenta-se nas posições 
pós-estruturalistas e pós-modernas e defende que os modelos de conhecimento se baseiam em experiências localizáveis. As representantes desta tendência refutam o conceito universal de "mulher" para reivindicar a pluralidade das "mulheres". A chave epistêmica desta perspectiva encontrase na "ressignificação" (mais do que na desconstrução) das identidades e da política. Judith Butler (2003, p. 210) advoga por "uma proliferação de identidades subversivas a modo de prática política”.

Sandra Harding (1996) caracteriza as três tendências como “epistemologias transicionais", porque, a seu modo de ver, estão enraizadas em culturas que são em si mesmas transicionais, o que gera dificuldades no sentido de prevalência de um único ponto de vista, ou seja, para a autora, as três tendências poderiam convergir sem maiores contradições.

Destacamos que, atualmente, as Epistemologias Feministas têm se consolidado como uma opção reconhecida no campo científico, trazendo para o debate a importância da interseccionalidade, revelando uma preocupação com o aumento de múltiplas formas de desigualdade social, discriminação, exploração, opressão e dominação que tem atingido, principalmente as mulheres em todo o mundo. Neste sentido, um Serviço Social com perspectiva feminista parte do pressuposto que os problemas sociais, as demandas postas por nossas/os usuárias/os (majoritariamente mulheres) requerem, também, análises feministas para a construção do conhecimento.

\section{Desafios na incorporação da perspectiva feminista pelo Serviço Social no Brasil}

A perspectiva feminista se inscreve no paradigma teórico dos Estudos Feministas e a perspectiva de gênero é sinônimo de enfoque de gênero, está baseada na teoria de gênero e na análise de gênero (LAGARDE, 1996).

Para o caso brasileiro, vislumbramos o Serviço Social como uma profissão que ainda luta por alcançar um dos objetivos pendentes: outorgar status acadêmico e de igualdade aos saberes que se produzem por mulheres, com mulheres e sobre as mulheres, que tem sido - e segue sendo - uma coluna central da profissão; em grande medida, somos mulheres que estudamos e produzimos sobre as origens e consequências das desigualdades de gênero e suas interseccionalidades.

A maioria das publicações brasileiras sobre os temas "Feminismo e Serviço Social" ainda centram suas discussões na "crítica marxista à noção de gênero", como é o caso do livro "Feminismo, diversidade sexual e serviço social”, das autoras Mirla Cisne e Silvana dos Santos (2018,), em cuja apresentação se lê:

Sob a perspectiva do feminismo, [o livro] apresenta a crítica marxista à noção de gênero, as particularidades da questão social e 
4 Sinopse sobre o livro apresentada na contracapa pela Editora Cortez, que o publicou. Disponível em: http://www.cortezeditora.com.br/ feminismo-diversidade-sexual-eservico-social-2317.aspx/p mostra como o patriarcado, o racismo e o heterossexismo adensam a exploração da classe trabalhadora e a violação de direitos. [...] Um convite à reflexão crítica sobre por que as profissões, e em particular o Serviço Social, devem considerar a defesa do feminismo e da diversidade como indispensáveis à luta anticapitalista ${ }^{4}$.

Em pesquisa doutoral em andamento, após levantamento realizado em periódicos brasileiros vinculados aos programas de pós-graduação na área do Serviço Social sobre o tema "violência doméstica e familiar contra a mulher", publicados entre os anos de 2007 a 2017, identificamos que nos artigos sobressaem de forma preponderante análises circunstanciadas em referenciais marxistas (SILVA, 2008; COELHO et al., 2014; COSTA, 2017; GROSSI; COUTINHO, 2017). O marcador de classe acompanha o eixo de análise que demarca as assimetrias na divisão sexual do trabalho no âmbito da agricultura e no trabalho doméstico (GROSSI; COUTINHO, 2017) e delimitam que as "[...] desigualdades de gênero fazem parte da totalidade da vida social e estão perfeitamente articuladas com a lógica do sistema capitalista, que transforma diferenças em desigualdades e opressões" (COSTA, 2017, p. 37).

Este tipo de análise sobre a violência de gênero é fruto de uma determinada diretriz curricular que rege a formação profissional, na medida em que os principais cursos de graduação e pós-graduação em Serviço Social no Brasil ainda privilegiam a matriz marxiana em seu processo de formação e, raramente, abrem espaço para linhas de pesquisa alternativas, como é o caso dos Estudos Feministas e de gênero. Esse fato limita o campo discursivo e a produção de um saber acadêmico plural, o que nos leva a indagar: como uma profissão que declara em seu do Código de Ética Profissional, Princípio VII, "Garantia do pluralismo, através do respeito às correntes profissionais democráticas existentes e suas expressões teóricas, e compromisso com o constante aprimoramento intelectual", tenta silenciar outras perspectivas teórico-metodológicas capazes de subsidiar a intervenção profissional e a produção do conhecimento em Serviço Social?

Consideramos que ocorre uma "cegueira ideológica" (LISBOA; OLIVEIRA, 2015) em parte da categoria profissional e que já não é mais possível fechar os olhos diante de uma realidade tão evidente. Os feminismos, de maneira geral, reconhecem a contribuição teórica do marxismo, aceitando entre outras, a concepção de práxis social, um contínuo movimento em espiral que valoriza a experiência como determinante da construção do saber. Porém, a complexidade das realidades de opressão, submissão, discriminação e exploração favorece a resistência das mulheres em "lugares de fala", tempos e contextos diversos, levando-as a romper as barreiras do silêncio por meio da linguagem e da ação. 
Face ao exposto, pensadoras negras latino-americanas e brasileiras como Sueli Carneiro (2003), Lelia Gonzales (1984), Luiza Bairros (2014) e Djamila Ribeiro (2017), defendem a necessidade do reconhecimento de outros saberes, a importância de entendê-los como localizados e de romper com o postulado do silêncio. Expõem crítica contundente quando declaram que militantes, organizações e integrantes dos movimentos de mulheres negras empreenderam um salto de qualidade, ao pronunciar e refletir sobre a interseccionalidade que permeia as suas trajetórias de vida - a partir do "lugar de fala": "O falar não se restringe ao ato de emitir palavras, mas de existir" (RIBEIRO, 2017, p. 64). Para a autora, o lugar que ocupamos socialmente nos faz ter experiências distintas e outras perspectivas. A hipótese de Djamila é que:

A partir da teoria do ponto de vista feminista, é possível falar de lugar de fala. Ao reivindicar os diferentes pontos de análises e a afirmação de que um dos objetivos do feminismo negro é marcar o lugar de fala de quem se propõem, percebemos que essa marcação se torna necessária para entendermos realidades que foram consideradas implícitas dentro da normatização hegemônica. (RIBEIRO, 2017, p. 60).

Pensar lugar de fala para essas autoras seria desestabilizar e criar fissuras e tensionamentos a fim de fazer emergir não somente contradiscursos, mas igualmente outros discursos construídos a partir de outros referenciais e de outras geografias.

Por outro lado, uma preocupação se destaca, quando constatamos que poucas Escolas de Serviço Social brasileiras incluem disciplinas do campo feminista no currículo de formação. Em levantamento feito por Daiana Nardino Dias (2014) sobre as matrizes curriculares dos cursos de graduação de 31 Instituições de Ensino Superior (IES), no ano de 2013, foi verificado que apenas seis delas ${ }^{5}$ integram a disciplina sobre "Relações de Gênero" na grade curricular obrigatória, e, na maioria das vezes, de forma complementar, no diálogo com outras categorias como raça/etnia, identidade, sexualidade entre outras. Em outras dez instituições, ${ }^{6}$ a temática de gênero aparece como disciplina eletiva, e 15 escolas sequer a incluem na grade curricular - nem em disciplinas obrigatórias, nem em eletivas (optativas).

Apesar dessa polêmica, a discussão sobre as diferentes perspectivas que englobam as questões de gênero tem ocorrido nos dois principais encontros nacionais da categoria: Congresso Brasileiro de Assistentes Sociais (CBAs) e Encontro Nacional de Pesquisa em Serviço Social (ENPESS), fazendose presente transversalmente em diferentes eixos, destacando-se os temas da "Violência contra a Mulher" (em primeiro lugar), seguidos de mesas coordenadas e apresentação de trabalhos que envolvem os temas "Gênero e Saúde" e "Gênero e Trabalho", entre outros.
5 As instituições de ensino que incluem a temática de gênero em suas grades curriculares como disciplina obrigatória são: UFMT/ MT;UnB/DF; Emescam/ES; UFF/ RJ; UFRJ/RJ; PUC/RS.

6 As instituições de ensino que incluem o debate sobre as questões de gênero em disciplinas optativas ou eletivas na grade curricular são: FUFSE/SE, Ufal/AL, UFMA/ MA, UFPE/PE, UFRN/RN, Ufam/AM, UFPA/PA, Ufes/ES, Uerj/RJ e UFSC/SC. 
7 Organizada em conjunto com o Grupo de Trabalho e Pesquisa (GTP) Serviço Social, Relações de Exploração/Opressão de Gênero, Raça/Etnia, Geração, Sexualidades, vinculado à ABEPSS, a chamada para essa publicação recebeu 122 artigos, e, segundo as editoras da revista, essa temática foi a que mais mobilizou, até então, o envio de trabalhos para publicação, na atual gestão.
Destaca-se a presença de pesquisadoras e profissionais de Serviço Social em mesas-redondas e simpósios temáticos nos encontros internacionais como o "Seminário Internacional Fazendo Gênero", que ocorre desde 1994 na UFSC, e reúne, a cada dois anos, pesquisadores(as) do mundo inteiro que atuam no campo dos Estudos Feministas.

Especial destaque merecem os dois volumes da Revista Temporalis, publicados no segundo semestre de 2014, sobre o tema Serviço Social, relações de exploração/opressão de gênero, raça/etnia, geração, sexualidades ${ }^{7}$. $\mathrm{O}$ volume de artigos e a diversidade de questões abordadas traçam um panorama do que vem sendo discutido no Serviço Social sobre as questões de gênero e indicam, igualmente, que os processos sociais e históricos vêm impondo as discussões de gênero à profissão e que há necessidade de ampliação do debate e da apropriação desses estudos pela categoria.

Além disso, temos um perfil próprio de feminismos na América Latina, como sinaliza María Luisa Femenías (2007), resultado da convergência e das contradições das suas três raízes: índígena, negra, europeia (além das migrações asiáticas, entre outros povos). Consideramos que nossas questões específicas favorecem discursos alternativos e uma ruptura político-epistemológica dos contextos naturalizados para darmos voz própria às múltiplas forças étnicas, sexuais, econômicas e culturais deste imenso país. A crítica feminista vem demonstrando que preterir essas múltiplas desigualdades como problema e invisibilizar a produção teórica das mulheres, contribui para reforçar as instituições e práticas políticas excludentes.

A literatura mais recente sobre políticas de igualdade tem incorporado a interseccionalidade nas políticas públicas, e um dos aspectos centrais dessa abordagem diz respeito à necessidade de se evitar a sobreposição de categorias de diferenciação, ou seja, perceber que as categorias - discriminação de gênero, raça, etnia, geração, exploração de classe, biopolítica dos corpos, entre outras, estão profundamente imbricadas e produzem efeitos distintos, dependendo do contexto analisado. A partir dessas discussões, pretendemos trazer algumas reflexões sobre as contribuições das epistemologias feministas para os estudos de gênero no Serviço Social.

\section{Interseccionando os múltiplos sistemas de subordinação: por um conhecimento "socialmente situado"}

A ideia central da Epistemologia Feminista é que "o conhecimento está/é sempre socialmente situado” (HARDING, 1996, p. 7): o que se conhece e o modo como se conhece reflete as experiências, circunstâncias e perspectivas físicas, psíquicas e sociais particulares dos sujeitos; ou seja, não somente a sua corporeidade, seus valores, suas habilidades, seus estilos 
cognitivos, senão também sua localização social: gênero, orientação sexual, raça/etnia, idade, status familiar, papéis que ocupa na sociedade, relações sociais - ocupação, filiação a um partido político, entre outros, ou seja, cada um/a de nós possui uma identidade social atribuída, e uma identidade subjetiva.

A ideia de conhecimento situado rompe com a noção de um sujeito epistemológico abstrato. $\mathrm{O}$ olhar (ou a perspectiva) torna-se encarnado, toma corpo em função dos marcadores sociais que o acompanharam durante toda a vida, incidindo sob sua capacidade funcional entre outros aspectos. O pressuposto do conhecimento situado é indagar: sob que circunstâncias estou fazendo essa afirmação? Para Donna Haraway (1995), existe uma subjetividade encarnada nos projetos feministas, e para a autora, o "situado" implica reconhecer os múltiplos posicionamentos do sujeito que conhece e do sujeito que será conhecido: cada pessoa se encontra inserida em uma complexa rede de posições, identidades e pontos de vista múltiplos, instáveis, inclusive contraditórios, e carregados de relações de poder.

Ao introduzir o conceito de interseccionalidade, Kimberle Crenshaw (2002) refere-se a uma associação entre múltiplos sistemas de subordinação, ou seja, situações em que ocorrem dupla ou tripla discriminação. Para a autora, "[...] a interseccionalidade é uma conceituação do problema que busca capturar as consequências estruturais e dinâmicas da interação entre dois ou mais eixos da subordinação" (CRENSHAW, 2002, p. 177).

Kimberle utiliza uma metáfora de intersecção, fazendo uma analogia com um cruzamento de avenidas em que os vários eixos de poder, isto é, raça, etnia, gênero e classe constituem as ruas que estruturam os terrenos sociais, econômicos e políticos. "Essas vias são por vezes definidas como eixos de poder distintos e mutuamente excludentes; o racismo, por exemplo, é distinto do patriarcalismo, que por sua vez é diferente da opressão de classe" (CRENSHAW, 2002, p. 177).

A autora nos adverte que tais sistemas, frequentemente, se sobrepõem e se cruzam, criando intersecções complexas nas quais dois, três ou quatro eixos se entrecruzam. Por exemplo, as mulheres negras estariam mais sujeitas a serem atingidas pelo intenso fluxo de tráfego em todas essas vias, uma vez que comumente estão posicionadas em um espaço onde o racismo ou a xenofobia, a classe e o gênero se encontram.

Em relação ao conceito "raça", justificamos em nota anterior a utilização da forma "raça/etnia", como uma conjugação da noção biológica de "raça" com a antropológica de "etnia”, a qual normalizará a diferença racial na cultura de massas, tornando "a ideia de 'raça' epistemologicamente correta"(GILROY,2007,p.81). Se "raça" engloba características fenotípicas, como a cor da pele, tipo de cabelo, conformação facial e cranial; "etnia" compreende fatores culturais, como a nacionalidade, afiliação tribal, religião, língua e tradições de um determinado grupo. 
8 Ao utilizarmos a expressão “o saber surge da prática”, ao invés de“o saber surge da práxis”, temos como pressuposto incentivar as pesquisadoras, docentes e profissionais do Serviço Social a refletirem sobre suas práticas, pois no nosso entender-e é o que o artigo propõe, no cotidiano de intervenção profissional surgirão reflexões sobre os Estudos Feministas e suas interseccionalidades.
O atual posicionamento da militância e do pensamento negro reflete o surgimento de novas formas de se compreender as relações raciais no Brasil que tem configurado um debate polêmico e, por vezes, até conflituoso. Corremos o risco de sair, de uma ideologia que afirmava "não existir racismo", o mito da democracia racial, rumo à afirmação radical da ideia de "raça" e da ideologia do "separatismo racial". Porém, quando o lugar da fala "interrompe o diálogo" e silencia o outro, adverte Marcia Tiburi (2017, [s. p.]): “[...] então ele já não é mais um lugar político, mas um lugar autoritário que destrói a política no sentido das relações humanas que visam ao convívio e à melhoria das condições da vida em sociedade”.

Há posicionamentos como o de Marilise dos Reis (2010), para quem, a "raça" deve ser desconstruída e refutada por sua utilização histórica de subalternização da população negra. Todavia, acreditamos que a substituição ou inutilização do termo não resulta no desaparecimento das práticas que nele se amparam. Dessa forma, concordamos com as colocações de Magrini (2015) quanto à utilização do conceito:

[...] mesmo sabendo da importância dos estudos que questionam a utilização do termo raça como categoria analítica, julgamos que na América Latina e principalmente no Brasil, ainda é fundamental o emprego do conceito, visto que a invizibilização [sic], durante anos, da discussão racial criou uma forte barreira do combate ao racismo e as arbitrariedades e violências anunciadas pela cor da pele. (MAGRINI, 2015, p. 39-43).

Ainda prevalece, entre as mulheres, um deslocamento das desigualdades sociais, ou seja, um aumento nas diferenciações sociais e étnicas: se as mulheres brancas enfrentam dificuldades, por conta das desigualdades de gênero, as mulheres negras enfrentam problemas muito maiores, pela junção da desigualdade de gênero e raça/etnia, além da social (de classe). Essa reflexão traz para o debate feminista, a discussão de como evitar um provável reducionismo de uma categoria sobre as demais, ou sobre um possível "essencialismo da diferença", nos convidando a perseguir sempre a macro análise ou o estudo das inter-relações de várias maneiras de diferenciação social.

\section{O saber surge da prática ${ }^{8}$ - experiências marcantes para a produção de conhecimento em Serviço Social.}

A complexidade e o entrecruzamento (interseccionalidade) das questões sociais requerem da(o) profissional de Serviço Social uma clareza do referencial teórico que orienta o seu exercício profissional em um movimento constante de construção e reconstrução de conceitos ou paradigmas de análise sobre a leitura da realidade. É nosso dever, 
como profissionais de Serviço Social, nos opormos a toda a ordem de discriminação, seja por razões de cultura, identidade de gênero, sexo, idade, cor da pele ou outras características físicas, orientação sexual, estado civil, descapacidade, ideias religiosas, entre outros.

No decorrer de sua história, o processo de Reconceituação do Serviço Social no Brasil inseriu a profissão nas lutas pelo enfrentamento a todas as formas de exploração, discriminação e preconceito, assinalando em seus Documentos Araxá (1968), Teresópolis (1970) e Sumaré (1978), um debate sobre a formação capaz de acompanhar as mudanças sócio-históricas, demandando teorias que refletiam sobre o contexto socioeconômico, político e cultural.

O período de Reconceituação (1970-1980) foi um expoente na história da nossa profissão, ao reivindicar um olhar específico para a realidade brasileira, cujo auge do processo de industrialização deixou milhares de famílias em situação de extrema pobreza. Surgiu um Serviço Social engajado e militante, comprometido com as lutas políticas do povo e a "teoria marxiana" foi definida como legado de uma profissão que exige respostas a esta nova conjuntura.

Um longo tempo se passou desde aquela época, e a realidade foi se reconfigurando em um incessante movimento dialético demandando o repensar das teorias. Nossas intervenções no cotidiano da prática foram revelando a importância de aceitarmos o fato de que as teorias são provisórias, de que é preciso colocá-las em movimento, visualizando-as mais como pressupostos do que categorias fixas e imutáveis. Para Cecilia Minayo (2010), os temas abordados em pesquisas na área das Ciências Humanas e Sociais, geralmente são entrelaçados, necessitando dos olhares (enfoques) de várias disciplinas, para que estas possam dialogar entre si em busca de respostas a problemática central.

Isto posto, trazemos a contribuição dos Estudos Feministas para o Serviço Social, concordando com as autoras González Garcia e Pérez Sedeno (2002), para as quais os Estudos Feministas não pretendem afirmar que "as mulheres vão fazer outra ciência", e, da mesma forma, assentimos a Sandra Harding (1996) e Maria Mies (2002), para as quais "não existe um método feminista", mas sim, várias "maneiras científicas" de ascender ao conhecimento, incluindo o saber que surge da prática e os saberes populares, como listado a seguir: o conhecimento político - que identifica as estratégias e habilidades utilizadas pelos sujeitos de nossas pesquisas; o conhecimento crítico - que possibilita criticar as ideologias, as teorias e desmistificá-las; o conhecimento técnico - que desenvolve habilidades, cria ferramentas, instrumentais técnico-operativos para intervir com pessoas e grupos, articulando as descobertas empíricas com as afirmações teóricas; o conhecimento social - que amplia a capacidade de 
relacionar-se com pessoas, de reconhecer as condições em que sobrevivem; que desenvolve novas formas de relação social abrindo-se para o "outro", para as "diferenças"; que reconhece que os indivíduos vivem determinadas relações entre si e seu entorno material, sociocultural e histórico; e por fim, o autorreconhecimento - que nos torna capazes de compreender e aceitar as nossas próprias capacidades e limitações teórico-metodológicas.

Nesse sentido, as escolhas de nossos objetos, tanto de estudo como de intervenção, demandam uma identificação com o sujeito/objeto; requerem, também, uma leitura da realidade que transpassa a esfera macro para a micro e vice-versa, em um processo dialético contínuo, de construção e reconstrução da teoria a partir da prática. Neste ponto, a experiência profissional, no cotidiano de intervenção, com os sujeitos da investigação e no processo formativo consiste em um processo no qual tomamos a realidade como ponto de partida, explicitando justamente os dados não reconhecidos, não valorizados, invisibilizados.

A perspectiva feminista valoriza a escuta dos sujeitos de nossas intervenções: mulheres, homens, jovens, idosos, trabalhadores, entre outros, para saber o que pensam e como se sentem, e formular perguntas de pesquisa a partir da "experiência desses sujeitos", bem como propostas de intervenção a partir dos interesses e necessidades dos mesmos. A introdução da categoria "experiência" ou do fator subjetivo na ciência corresponde ao lema feminista: "o pessoal é político", ou seja, questões que até agora eram vistas como pertencentes à esfera privada, por exemplo, "em briga de marido e mulher não se mete a colher", tornam-se pautas de políticas públicas e as mulheres contribuem tanto na proposição dessas políticas, como na construção de conhecimento, na medida em que relatam suas experiências para os(as) profissionais de Serviço Social ou para o(a) pesquisador(a).

Assim, as pessoas com as quais trabalhamos somente podem emergir como sujeitos no horizonte da produção do conhecimento ou da pesquisa científica na medida em que desvendamos com elas seus mistérios, suas vivências, sua condição de subalternas, oprimidas ou exploradas. E essa passagem - da condição de objeto para a condição de sujeito - apenas acontece mediada pela nossa própria emancipação, como intelectuais engajados(as) e identificados(as), produzindo conhecimento.

\section{Entrelaçando diferentes experiências de intervenção profissional - práticas sociais e diversidades}

A nossa aproximação com os Estudos Feministas aliada à prática docente de acompanhamento pedagógico em estágio curricular nos sensibilizou para as seguintes questões: "nossas(os) profissionais estão preparadas(os) para intervir junto aos diferentes tipos de violências de 
gênero?" e "Como conviver, respeitar estudantes, professores, e profissionais com diferentes orientações sexuais, bem como usuárias(os) com múltiplas identidades de gênero no cotidiano de nossas práticas?”.

A produção do conhecimento - os Trabalhos de Conclusão de Curso, as Dissertações de Mestrado e Teses de Doutorado - tem revelado que os(as) estudantes mergulham em experiências de campo (no estágio ou na pesquisa), a partir do que podemos afirmar que nenhum trabalho teórico é alheio à experiência vivenciada pelo sujeito que o escreveu. Nesse processo surgem novas experiências, conforme constatamos uma interseccionalidade nos temas para reflexão. Cada vez mais frequentes, os Trabalhos Acadêmicos têm revelado estudos sobre mulheres moradoras de rua, mulheres negras, indígenas, camponesas, homoafetividades, violências de gênero, interrupção legal da gravidez, discriminação racial, política de cotas entre outros. A partir daqui, abre-se um conjunto de possibilidades que privilegiarão o lugar que nós, profissionais, produtoras de conhecimento daremos aos Estudos Feministas.

O curso de Serviço Social de caráter generalista insere estudantes em campos de estágio ou profissionais para atuar em diferentes espaços junto a um vasto campo de políticas públicas. Nesse sentido, recorrer a teorias que norteiem a compreensão sobre equidade de gênero nas políticas públicas, novos modelos de família, violências de gênero, pessoa com deficiência, pessoa idosa, o cyberativismo (violência digital, cyber bulling), e outros são essenciais para qualificar o debate, as experiências de práticas e a postura ético-política de nossos(as) estudantes e profissionais.

Tendo claro que o Serviço Social cumpre um papel decisivo no enfrentamento da cultura de opressão, no decorrer da nossa prática, constatamos que uma profissão se legitima a partir das respostas que consegue emitir para usuárias(os) dos seus serviços e para suas(seus) contrastantes. Nesse sentido, nossa prática cotidiana, tanto na academia como na militância, permitiu-nos destacar uma experiência que merece ser compartilhada e revelada pela tríade do ensino, da pesquisa e da extensão.

\section{Práticas de ensino libertadoras: a sala de aula como um espaço de desafio}

Os cursos de Serviço Social das unidades de ensino superior no Brasil são regidos por diretrizes curriculares e têm em sua estrutura, componentes apresentados em forma de disciplinas obrigatórias, eletivas, Trabalhos de Conclusão de Curso, estágio obrigatório e atividades complementares, necessários ao processo de formação.

Em pesquisa abrangendo 32 universidades públicas e privadas das cinco regiões do país ${ }^{9}$, Rita de Lourdes de Lima (2012 apud DIAS, 2014), constatou que as disciplinas que se dedicam a estudar as relações
9 As unidades de ensino pesquisadas foram: Região Norte: UFAM e UFT; Nordeste: UFPE, UFAL, UFRN, UFMA, FAMETRO (CE), UFPB, IFCE, UECE, UERN, UEPB, UFRB; Centro-oeste: UNB, UFMT, UFG, PUC-GO, UNIVAG-MT; Sudeste: UFJF, UERJ, UFRJ, UFES, UFF, PUCRIO, Unilago São João do Rio Preto (SP), UNINOVE (SP), Centro Universitário Ítalo Brasileiro (SP); Sul: PUC-RS, UFSC, UNISINOSRS, UNIPAMPAS (RS) e Universidade Caxias do Sul (RS). (LIMA, 2012). 
10 Ambas as Unidades de Ensino são o local de trabalho das autoras do presente artigo.

11 A disciplina foi ministrada por uma das autoras deste artigo. sociais de gênero e suas interseccionalidades geralmente são oferecidas no último ano do curso, quando os(as) discentes estão no final do estágio, “[...] dificultando, portanto, a percepção por parte destes [estudantes] sobre as questões ligadas às relações sociais [interseccionalidade] durante o estágio" (LIMA, 2012, p. 13).

A partir do seu estudo, a autora sugere as seguintes propostas para os cursos de graduação em Serviço Social: a) A temática de gênero deve se dar em forma de disciplina obrigatória e no momento de ingresso dos discentes no estágio obrigatório; b) A temática de gênero deve incorporar mais efetivamente discussões relacionadas à [interseccionalidade] raça/ etnia, diversidade sexual, entre outras questões; c) A temática de gênero deve se dar também transversalmente, nas diversas disciplinas do curso, relacionando tal temática com as demais (LIMA, 2012, p. 14).

Para os propósitos deste artigo, assinalamos sumariamente uma experiência realizada na formação profissional, que oportunizou a abordagem de gênero e Serviço Social, por meio de disciplina optativa (eletiva).

As realidades aqui anunciadas tiveram seus desdobramentos por meio de disciplinas optativas ofertadas no período de 2013 a 2017 nos cursos de Serviço Social da Universidade Federal de Santa Catarina (UFSC) e da Universidade Federal de Sergipe (UFS) ${ }^{10}$, a abordagem central das ementas contemplaram relações de gênero, feminismos e Serviço Social, no qual discentes de diferentes cursos regularmente matriculados, tiveram uma aproximação ao pensamento teórico feminista para subsidiar estudos e discussões de conteúdos acerca de temas sobre a violência contra a mulher.

Em relação à Universidade Federal de Santa Catarina (UFSC), salientamos uma experiência no primeiro semestre de 2015, no qual foi oferecida a disciplina optativa (eletiva): "Tópicos Especiais em Movimentos Sociais - Mulheres em Movimento e o papel do Serviço Social"11, tendo como ementa "Aspectos conceituais e metodológicos sobre os movimentos feministas e de mulheres no Brasil. O papel dos movimentos feministas nas transformações socioculturais, nas áreas dos direitos humanos, cidadania, exclusão social e violência contra mulheres. [...] As contribuições dos estudos feministas e das metodologias de trabalho com mulheres para o Serviço Social". A disciplina trouxe como um dos principais objetivos aprofundar o debate teórico-conceitual que conduziu à formulação das categorias analíticas centrais: relações de gênero, classe, raça/etnia e gerações junto aos movimentos feministas, LGBTTs e de mulheres. Matricularam nesta disciplina, 42 estudantes dos cursos de Serviço Social, Ciências Sociais, Nutrição, Geografia, História, Jornalismo, Língua e Literatura e Secretariado, configurando uma interdisciplinaridade que ao longo do semestre, enriqueceu e diversificou as discussões, além da presença de uma 
estudante integrante dos povos indígenas Laklaño Xokleng (Ibirama/ $\mathrm{SC})$. Como procedimento metodológico adotado ao processo ensinoaprendizagem, a realização de trabalho de grupo reuniu um conjunto de ações compartilhadas por equipes de estudantes que abordaram diferentes Movimentos, a saber: Movimento de Mulheres Negras, Movimento de Mulheres Indígenas, Movimento LGBTTs, A Marcha das Vadias, entre outros, com o objetivo de conhecê-los e trazer integrantes desses grupos para a sala de aula. Tivemos o privilégio de escutar e conhecer a "cacica" Zenaide, que falou das principais lutas e conquistas do seu povo, que vive no "Morro dos Cavalos", nas proximidades de Florianópolis. Também recebemos uma representante do Movimento de Mulheres Negras, e uma transexual que falou sobre a sua experiência de vida, salientando a dificuldade em relação a conseguir trabalho, decorrente do elevado grau de transfobia que ainda impera na sociedade. Notadamente, foi possível perceber que a temática da violência de gênero perpassava todos os Movimentos de Mulheres ou Feministas estudados, razão pela qual estudos mais aprofundados desencadearam a produção em vídeo e a elaboração do Projeto "Violência de Gênero: representações em foco" que, elaborado de forma interativa entre docente e discentes, oportunizou a participação de todos(as), como também a assinatura de um Termo de Consentimento Livre Esclarecido, confirmando a autorização de suas falas e suas imagens.

$\mathrm{Na}$ Universidade Federal de Sergipe (UFS), com sede no município de São Cristóvão, a oferta da disciplina Relações de Gênero e Serviço Social também ocorreu no primeiro semestre de 2013. Respondendo a uma demanda reprimida dos(as) estudantes por disciplinas optativas ocorridas naquele período, foram abertas duas turmas, que contaram com aproximadamente 91 matriculados(as), distribuídos em horários vespertino e noturno. A apresentação da ementa contemplava dentre os eixos centrais: "O feminismo - antecedentes históricos. [...] Matrizes teóricas nos estudos feministas da mulher: patriarcado, divisão sexual do trabalho e gênero. Abordagens da subjetividade e construção da identidade de gênero. [...] Inserção do gênero nas políticas sociais. Estudos empíricos: gênero e serviço social". Os objetivos da disciplina destacavam conhecer historicamente o significado de gênero e feminismo sob diferentes perspectivas teóricas; articular a questão de gênero com o serviço social, no âmbito das dimensões teórico-metodológicas, ético-políticas e técnico-operativas da profissão. As leituras instigaram profícuos e calorosos debates, de modo articulado com o Serviço Social, em razão da presença unânime de estudantes do curso. Além disso, o processo avaliativo contou com a liberdade de escolha sobre a temática de gênero, o que resultou em uma produção de conhecimento consistente, permitindo um olhar mais atento e desvencilhado de preconceitos sobre violência no espaço intrafamiliar contra a mulher e a 
criança, união por casais homoafetivos, divisão sexual do trabalho no espaço rural, dentre outros.

\section{Considerações conclusivas}

Procuramos, neste ensaio, dialogar com a categoria (Assistentes Sociais) sobre a importância da pesquisa e da produção do conhecimento em Serviço Social, destacando a contribuição que as Epistemologias Feministas têm proporcionado no processo dialético que ocorre entre a investigação e a ação (intervenção), o que nos aponta novos caminhos para a interseccionalidade. A incorporação das experiências e vozes das mulheres tem levado, nas teorias feministas e no Serviço Social, à emergência de novos objetos de pesquisa e novas perspectivas epistemológicas e metodológicas. Entendemos que a construção do conhecimento não é de domínio exclusivo dos centros de ensino e pesquisa. Por essa razão, é essencial continuar vinculando, articulando e retroalimentando o mundo acadêmico com o profissional, para que um dos princípios históricos mais caros do Serviço Social: "conhecer para atuar e investigar para intervir", possa continuar vigorando.

Um Serviço Social com perspectiva de gênero torna-se mais evidente na medida em que as e os estudantes possam ser capacitados(as) com ferramentas teóricas e metodológicas que venham ao encontro do cotidiano de intervenção nos campos de estágio, das práticas profissionais, trazendo à tona as múltiplas formas de desigualdade e propondo caminhos para transformações sociais. A consolidação de uma disciplina, de uma área ou de uma profissão passa pela produção de conhecimentos próprios, e isto apenas será possível a partir de estudos e pesquisas centrados na realidade do Serviço Social. Este, por sua vez, tem-se inserido nas lutas pelo enfrentamento a todas as formas de discriminação e preconceito, e assinala que o debate sobre formação profissional acompanha as mudanças sóciohistóricas. Nessa direção, também é capaz de produzir outros olhares sobre os feminismos, constituindo objeto de investigação e intervenção, visto que, na academia, a presença feminina de estudantes, docentes, pesquisadoras e teóricas além de notória também é alvo de opressão, ameaça e violência acerca das questões de gênero, raça/etnia, classe, geração entre outras. Assim, podemos quastionar: "Como profissionais de Serviço Social, estamos conseguindo gerar saberes a partir de nossas práticas, produzindo análises críticas que apresentam propostas, alternativas aos problemas sociais?", "Estamos promovendo mudanças e melhoria na qualidade de vida das pessoas que atendemos (a maioria mulheres), que apostam por uma sociedade mais justa e igualitária?”.

Salientamos que os estudos feministas apresentam uma perspectiva crítica na construção do conhecimento, uma vez que foram as feministas 
que problematizaram a clássica distinção entre o público e o privado em espaços de subordinação que eram naturalizados a partir dessa visão, propondo o slogan: "o pessoal é político". Os feminismos abriram para contestação política novos enfoques da questão social, como: violências de gênero, modelos de família, corpo e sexualidade, divisão sexual do trabalho, o cuidado dispensado às crianças, idosos(as) e enfermos(as) atribuído somente às mulheres, entre outros.

Entendemos que a Epistemologia Feminista pode nos fornecer pistas, caminhos para repensarmos e ressignificarmos os conceitos e as questões sociais que envolvem o fazer profissional do Serviço Social. É importante destacar que a investigação feminista pode incidir em qualquer campo disciplinar (inclusive o Serviço Social), e requer uma perspectiva interdisciplinar uma vez que tem como pressuposto propor "questões de pesquisa" que se baseiam na pluralidade, na diversidade e na multiplicidade de experiências das mulheres. Também é consenso afirmar que "não existe um método feminista", que as pesquisas realizadas com enfoque feminista utilizam uma combinação crítica de métodos de investigação e de perspectivas de análise.

As experiências reveladas nesse ensaio indicam que a sala de aula continua sendo o espaço que oferece as possibilidades mais radicais na academia. Bell Hooks (2017) nos convida para uma renovação nas nossas práticas de ensino, conhecer o que está além das fronteiras do aceitável, para pensar e repensar, para criar novas visões, celebrar um ensino que permita as transgressões, para "transformar a educação em prática de liberdade".

Nossa experiência tem apontado quão necessário é estimular de modo contundente e crítico as discussões que permeiam as temáticas de gênero, raça/etnia, deficiência, classe, geração entre outras marcas que se constituem como violência contra a mulher na relação ensino/aprendizagem. Assim, consideramos como um dos grandes desafios, repensar a profissão sobre outras perspectivas, incorporando as epistemologias feministas no campo do processo formativo sem, contudo, restringir as análises a uma única perspectiva teórica: a marxista.

Que o Serviço Social possa aproximar-se das contribuições dos estudos feministas, e que, no cotidiano das nossas práticas, possamos incorporar reflexões teóricas que iluminem as demandas interseccionais que surgem no exercício profissional.

\section{Referências}

BAIRROS, L. Nossos feminismos revisitados. In: MIÑOSO, Y. E.; CORREAL, D. G.; MUÑOZ, K. O. (Ed.). Tejiendo de otro modo: Feminismo, epistemología y puestas descoloniales en Abya Yala. Popayán: Editorial Universidad del Cauca, 2014. p. 181-187. 
BLAZQUEZ GRAF, N. El retorno de las brujas. Incorporación, aportaciones y criticas de las mujeres a la ciencia. México: CEIICH - Universidad Nacional Autónoma de México, 2008.

BUTLER, J. P. Problemas de gênero: feminismo e subversão da identidade. Tradução de Renato Aguiar. Rio de Janeiro: Editora Civilização Brasileira, 2003.

CARNEIRO, S. Mulheres em movimento. Estudos avançados, São Paulo, v. 17, n. 49, p. 117-133, 2003.

CISNE, M.; SANTOS, S. M. de M dos. Feminismo, diversidade sexual e serviço social. Editora Cortez: São Paulo, 2018.

COELHO, V. P. C. et al. Reflexões sobre a violência: poder e dominação nas relações sociais de sexo, de. R. Pol. Públ., São Luís, v. 18, n. 2, p. 471-479, jul./ dez. 2014.

COLLINS, P. H. Black feminist thought: knowledge, consciousness, and the politics of empowerment. New York: Routledge, 2009.

COSTA, R. G. da. A política de enfrentamento à violência contra a mulher no Brasil: limites e possibilidades contemporâneas, Revista Direitos, Trabalho e Política Social, Cuiabá, v. 3, n. 4, p. 11-39, jan./jun. 2017.

CRENSHAW, K. Documento para o Encontro de Especialistas em Aspectos da Discriminação Racial Relativos ao Gênero. Revista Estudos Feministas, Florianópolis, UFSC, 2002. p. 171-188.

DIAS, D. N. O estado da arte sobre gênero no serviço social. 2014. 165 f.165 Dissertação (Mestrado em Serviço Social) -Pós-Graduação em Serviço Social, Universidade Federal de Santa Catarina, Florianópolis, 2014.

DOS REIS, M. L. M. Diáspora como movimento social: implicações para a análise dos movimentos sociais de combate ao racismo. Ciências Sociais Unisinos, São Leopoldo, v. 46, n. 1, p. 37-46, jan./abr. 2010.

EDITORA CORTÊS. Feminismo, diversidade sexual e Serviço Social. 2019. Disponível em: http://www.cortezeditora.com.br/feminismo-diversidade-sexuale-servico-social-2317.aspx/p. Acesso em: 20 set. 2018.

FEMENÍAS, M. L. Esbozo de um feminismo latinoamericano. Revista Estudos Feministas, v. 15, n. 1, p. 11-25, jan./abril 2007.

GILROY, P. Entre campos. São Paulo: Annablume, 2007.

GONZALES, L. Racismo e Sexismo na Cultura Brasileira. Revista Ciências Sociais Hoje, Anpocs, 1984, p. 223-244.

GONZÁLEZ GARCIA, M. I.; PÉREZ SEDEÑO, E. Ciência, tecnologia y género. Revista Iberoamericana de Ciencia, Tecnologia Sociedad y Innovación [online], n. 2, [s. p.], enero/abr. 2002. Disponível em: http://www.oei.es/revistactsi/ nemero2/varios2.htm. Acesso em: 20 set. 2018

GROSSI, P. K.; COUTINHO, A. R. C. Violência contra a mulher do campo: desafios às políticas públicas. Serviço Social em Revista, v. 20, n. 1, p. 25-40, 2017. http://www.uel.br/revistas/uel/index.php/ssrevista/article/view/32071/23366. Acesso em: 20 set. 2018. 
GUZMÁN,M.; PÉREZ,A. Las Epistemologías Feministas y la Teoría de Género. Cinta Moebio, Cinta, v. 22, p. 112-126, 2005. Disponível em: www.moebio.uchile. cl/22/guzman.htm. Acesso em: 20 set. 2018.

HARAWAY, D. Saberes localizados: a questão da ciência para o feminismo e o privilégio da perspectiva parcial. Cadernos Pagu, Campinas, v. 5, p. 7-42, 1995.

HARDING, S. Ciencia y Feminismo. Madrid: Ediciones Morata, 1996. p. 15-27.

HOOKS, B. Ensinando A transgredir. A educação como prática da liberdade. Tradução de Marcelo Brandão Cipolla. 2. ed. São Paulo: Editora WMF Martins Fontes, 2017

LAGARDE, M. Género y feminismo - desarrollo humano y democracia. Madrid: Horas \& horas, 1996.

LIMA, R. de L. de. Gênero e Serviço social. VI Congresso Internacional de estudos sobre a diversidade sexual e gênero da ABEH, Salvador, 2012.

LISBOA, T. K.; OLIVEIRA, C. N. Serviço Social com perspectiva de gênero: o que a "cegueira ideológica" não permite ver. Revista Feminismos, v. 3, n. 2/3, [s. p. ], 2012. Disponível em: http://www.feminismos.neim.ufba.br/index.php/revista/ article/view/312. Acesso em: 20 set. 2018.

MAGRINI, P. R. Produção Acadêmica sobre o MST: Perspectivas, Tendências e Ausências nos Estudos sobre Gênero, Sexualidade, Raça e suas Interseccionalidades. 2015. 279 f. Tese (Doutorado em Ciências Humanas) - Programa de PósGraduação Interdisciplinar em Ciências Humanas, Universidade Federal de Santa Catarina, Florianópolis, 2015.

MIES, M. Investigación sobre las mujeres o investigación feminista? El debate en torno da ciencia y la metodología feministas. Tradução de Glória Elena Bernal. In: BARTRA, Eli (Org.). Debates em torno a uma metodologia feminista. 2. ed. México: UNAM, 2002. p. 63-102.

MINAYO, M. C. de S. O desafio do conhecimento - pesquisa qualitativa em saúde. São Paulo: Hucitec; Rio de Janeiro: ABRASCO, 2010.

NICHOLSON, L. Interpretando o gênero. Revista Estudos Feministas, Florianópolis, v. 8, n. 2, p. 9, jan. 2000. Disponível em: https://periodicos.ufsc.br/ index.php/ref/article/view/11917. Acesso em: 21 set. 2018.

RIBEIRO, D. O que é lugar de fala? Belo Horizonte: Letramento: Justificando, 2017.

SALGADO, M. P. C. Metodologia de la investigación feminista. Colección Diversidad Feminista. Centro de Investigaciones Interdisiplinarias en Ciencias y Humanidades. Guatemala, 2008.

QUIJANO, A. Modernidad, identidad y utopia en América Latina. Cadernos de Sociologia da UFRGS, Porto Alegre, v. 5, n. 5, p. 9-23, 1993.

TIBURI, M. “Lugar de fala e lugar de dor”. Revista Cult, 29 mar. 2017. Disponível em: https://revistacult.uol.com.br/home/lugar-de-fala-e-etico-politica-da-luta. Acesso em: 20 set. 2018. 
VILLENA, A. M.; ROMERO, B. A. Trabajo Social e investigación: estrategias empoderadoras y de género en la universidad española. Trabajo Social, 20, n. 1, p. 71-101, 2007. Disponível em: https://revistas.unal.edu.co/index.php/tsocial/ article/view/71575. Acesso em: 10 abr. 2019.

Submetido em: 16/07/2018

Aceito em: 03/06/2019 


\title{
KNOWLEDGE IS NOURISHED BYTHE PRACTICES: TO A SOCIAL WORK BY FEMINIST PERSPECTIVE
}

\begin{abstract}
The article proposes an interlocution between Social Work and Feminist Studies in the process of knowledge construction, introducing the category intersectionality as one of the ways to deal with the multiplicity of differences we face in our professional daily lives. It discusses the reductionism of the Marxist dimension present in the publications on this subject in Brazil and understands that the category "gender" is an important element to understand and explain the status of the profession. The research work presents the three main tendencies of the Feminist Epistemology: the Standpoint Theory; the Feminist Empiricism; and the Feminist Postmodernism, whose points of distinction occur in the way the relationship between women and science is established. The central point is the epistemological value granted to the category "experience" of women. This study considers it important to reflect on the dialectic between the epistemological and the empirical, believing that knowledge (social research) is nourished by social intervention (of practices). It concludes that a "Social Work from a feminist perspective" will enable a greater engagement of professionals in the intervention processes.
\end{abstract}

Keywords: Social work. Feminist epistemologies. Intersectionality. Professional intervention.

\section{EL SABER SURGE DE UNA PRÁCTICA: POR UMTRABAJO SOCIAL BAJO UNA PERSPECTIVA FEMINISTA}

\begin{abstract}
Resumen
El artículo propone una interlocución entre el Trabajo Social y los Estudios Feministas en el proceso de construcción del conocimiento, con la introducción de la categoría interseccionalidad como una de las formas de tratar de la multiplicidad de diferencias que enfrentamos en nuestro cotidiano profesional. Amparadas en la Epistemología Feminista, cuestionamos el reduccionismo del Trabajo Social brasileño a una única corriente teórica, la marxista, que somete toda la complejidad de la vida social y humana a la esfera de la producción. El texto busca desvelar las fisuras que avanzan en el campo del conocimiento, en el sentido de contribuir con propuestas teóricas que atraviesan las fronteras interseccionales, transversales, interdisciplinarias entre las categorías género, raza/etnia, sexualidad, clase, generación entre otras. El trayecto argumentativo acompañará una secuencia de reflexiones realizadas a lo largo de años de experiencia, tanto en la práctica académica, como en los trabajos de campo realizados a través de Proyetos de Investigación y Extensión,.
\end{abstract}

Palabras-clave: Trabajo social. Epistemologías feministas. Interseccionalidad. Intervención profesional. 